Review

\title{
Epstein-Barr Virus in Gastric Carcinoma
}

Jun Nishikawa $^{1, *}$, Hironori Yoshiyama ${ }^{2}$, Hisashi Iizasa ${ }^{2}$, Yuichi Kanehiro ${ }^{2}$, Munetaka Nakamura ${ }^{1}$, Junichi Nishimura ${ }^{1}$, Mari Saito ${ }^{1}$, Takeshi Okamoto ${ }^{1}$, Kouhei Sakai ${ }^{3}$, Yutaka Suehiro $^{3}$, Takahiro Yamasaki ${ }^{3}$, Atsunori Oga ${ }^{4}$, Hideo Yanai ${ }^{5}$ and Isao Sakaida ${ }^{1}$

1 Department of Gastroenterology and Hepatology, Yamaguchi University Graduate School of Medicine, Minami-Kogushi 1-1-1, Ube, Yamaguchi 755-8505, Japan;

E-Mails: munetaka@yamaguchi-u.ac.jp (M.N.); nishimuj@yamaguchi-u.ac.jp (J.N.); mari-s@zj8.so-net.ne.jp (M.S.); tokamoto@yamaguchi-u.ac.jp (T.O.); sakaida@yamaguchi-u.ac.jp (I.S.)

2 Department of Microbiology, Shimane University Faculty of Medicine, 89-1 Enyacho, Izumo City, Shimane 693-8501, Japan; E-Mails: yosiyama@med.shimane-u.ac.jp (H.Y.); iizasah@med.shimane-u.ac.jp (H.I.); kanehiro@med.shimane-u.ac.jp (Y.K.)

3 Department of Oncology and Laboratory Medicine, Yamaguchi University Graduate School of Medicine, Minami-Kogushi 1-1-1, Ube, Yamaguchi 755-8505, Japan;

E-Mails: sakaik@yamaguchi-u.ac.jp (K.S.); ysuehiro@yamaguchi-u.ac.jp (Y.S.); t.yama@yamaguchi-u.ac.jp (T.Y.)

4 Department of Pathology, Yamaguchi University Graduate School of Medicine, Minami-Kogushi 1-1-1, Ube, Yamaguchi 755-8505, Japan; E-Mail: oga@yamaguchi-u.ac.jp

5 Department of Clinical Research, National Hospital Organization Kanmon Medical Center, 1-1 Sotoura, Chofu, Shimonoseki, Yamaguchi 752-8510, Japan;

E-Mail: yanaih@kanmon-mc2.hosp.go.jp

* Author to whom correspondence should be addressed; E-Mail: junnis@yamaguchi-u.ac.jp; Tel.: +81-836-22-2243; Fax: +81-836-22-2303.

Received: 28 May 2014; in revised form: 27 September 2014 / Accepted: 28 October 2014 / Published: 7 November 2014

Abstract: The Epstein-Barr virus (EBV) is detected in about 10\% of gastric carcinoma cases throughout the world. In EBV-associated gastric carcinoma, all tumor cells harbor the clonal EBV genome. Gastric carcinoma associated with EBV has distinct clinicopathological features, occurs predominately in men and in younger-aged individuals, and presents a generally diffuse histological type. Most cases of EBV-associated gastric carcinoma exhibit a histology rich in lymphocyte infiltration. The immunological reactiveness in the host may 
represent a relatively preferable prognosis in EBV-positive cases. This fact highlights the important role of EBV in the development of EBV-associated gastric carcinoma. We have clearly proved direct infection of human gastric epithelialcells by EBV. The infection was achieved by using a recombinant EBV. Promotion of growth by EBV infection was observed in the cells. Considerable data suggest that EBV may directly contribute to the development of EBV-associated GC. This tumor-promoting effect seems to involve multiple mechanisms, because EBV affects several host proteins and pathways that normally promote apoptosis and regulate cell proliferation.

Keywords: Epstein-Barr virus; gastric carcinoma; DNA methylation

\section{Introduction}

The Epstein-Barr virus (EBV) is associated with a variety of tumors derived from B cells, T cells, natural killer (NK) cells, and epithelial cells. Burkitt lymphoma [1], post-transplant lymphoproliferative disease [2], and Hodgkin's disease [3] are B-cell tumors. Peripheral T-cell lymphomas [3] and NK/T-cell lymphomas are T-cell tumors and NK-cell tumors, respectively. Nasopharyngeal carcinoma [1] and gastric carcinoma (GC) [3] are epithelial tumors.

Existence of the EBV genome in GCs was first detected in 1990 by Burke et al. using the polymerase chain reaction (PCR) technique [4]. Since then, about 10\% of GCs have been identified as EBV positive. In each EBV-positive case of GC, almost all carcinoma cells are infected with the virus [5,6], and tumor cells exist as a monoclonal proliferation of EBV-infected cells [7,8]. These facts suggest the significance of EBV in the development of GCs.

Gastric cancer is the second leading cause of cancer-related deaths globally, and $60 \%$ of these deaths occur in East Asia, which includes Japan [9]. The worldwide occurrence of EBV-associated GC is estimated at more than 50,000 cases per year [10]; therefore, EBV-associated GC is the most common cancer among EBV-related malignancies.

\section{Definition}

In addition to the detection of the EBV genome in GCs using PCR [4], EBV-encoded small RNA 1 (EBER1) was also detected using in situ hybridization (ISH). Various studies in the early 1990s indicated that EBV-associated GC comprises about $10 \%$ of all GCs worldwide [5-8]. EBER1 is highly abundant (10 million copies per cell) in individual infected cells. Typically, EBER1 can be detected in the nuclei of tumor cells; however, the EBER1 signal is negative in reactive lymphoid infiltrate cells or normal gastric mucosa cells (Figure 1). To make the diagnosis of EBV-associated GC before treatment, EBER1-ISH should be applied to gastric mucosal biopsy samples from patients who have undergone upper gastrointestinal endoscopy. Patients with EBV-associated GC have elevated levels of serum antibodies against EBV early antigen and EBV capsid antigen. However, EBV nuclear antigen (EBNA) 1 antibody titers do not show significant difference between patients and healthy counterparts [7]. 
Figure 1. Lymphoepithelioma-like subtype of Epstein-Barr virus (EBV)-associated gastric carcinoma. (a) H \& E staining; (b) EBV-encoded small ribonucleic acid 1 (EBER1) in situ hybridization demonstrates positive nuclei in the carcinoma cells, which are surrounded by infiltrating lymphocytes.

a

b

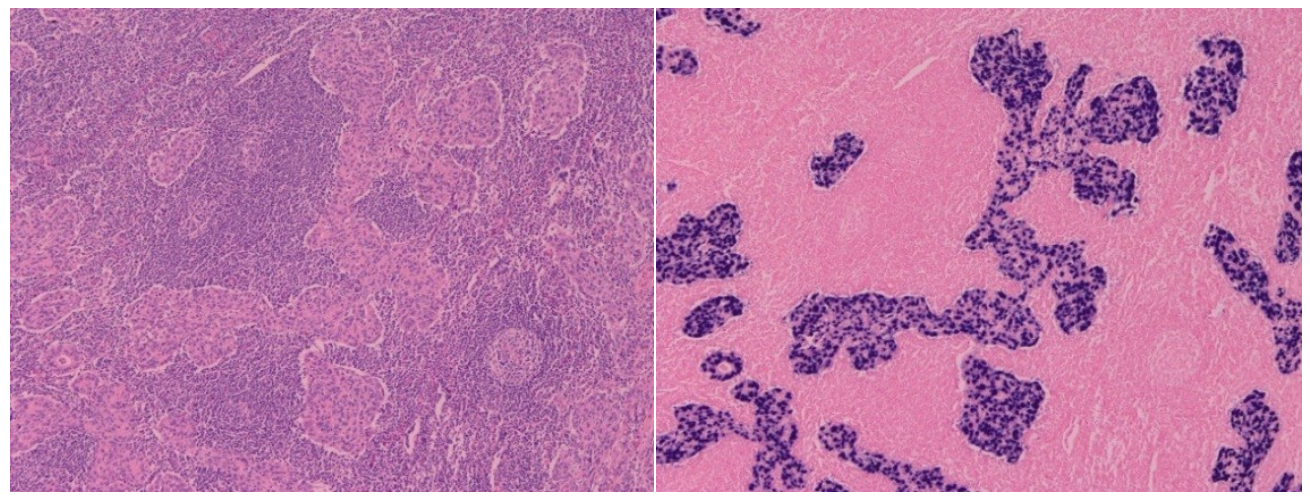

\section{Epidemiology}

$\mathrm{GC}$ is one of the most common malignancies in Japan. Among the various histological types from Japanese gastric cancer cases, the incidence of EBV-positive cases was 7.0\% in 1994 [7]. In contrast to Burkitt lymphoma and nasopharyngeal carcinoma, which are distributed endemically in equatorial Africa and Southeast Asia, respectively, EBV-associated GC is distributed worldwide in a similar proportion [10]. Regional difference in the incidence of EBV-associated GC is also reported. The incidence of EBV-associated $\mathrm{GC}$ in all cases of gastric cancer ranges from a high of $16 \%-18 \%$ in the USA and Germany to a low of $4.3 \%$ in China. The regional difference in the incidence of EBV-positive cases in gastric cancers indicates that the prevalence EBV-associated GC is inversely related to the incidence of GC [11].

EBV-associated GC has distinct clinicopathological features, is present predominately in men and in younger-aged individuals, and presents a generally diffuse histological type [12,13]. Most studies have not shown evident age dependence in the frequency of EBV-associated GC. Almost all of the studies showed male predominance of EBV-associated GC, suggesting that risks related to lifestyle or occupational factors may exist among males [14]. An interview study in Japan showed that salty food intake and exposure to wood dust and/or iron filings, which may induce mechanical injury to the gastric epithelia, are related to a higher risk of EBV-associated GC [15]. Camargo et al. recently showed that the association of smoking with gastric cancer is stronger for EBV-positive than EBV-negative tumors [16].

\section{Pathology}

EBV-associated GC has definite histological relevance to GC with lymphoid stroma (GCLS) [17-19], which was originally described by Watanabe et al. as a subtype of the carcinoma [20]. GCLS is a poorly differentiated adenocarcinoma with diffuse and intense lymphocyte infiltration similar to EBV-associated nasopharyngeal lymphoepithelioma. More than $80 \%$ of lymphoepithelioma-like GC is infected with EBV [17-19] (Figure 1), whereas ordinary-type GC, comprising 5\%-10\% of all cases of GC, shows features of moderately or poorly differentiated adenocarcinoma with various degrees of lymphocytic infiltration. 
Further infiltration of the carcinoma (tumor cells) into the submucosa is occasionally accompanied by EBV-associated GC generally exhibiting a characteristic histology referred to as GCLS [21].

EBV-associated GC has a null or gastric phenotype as determined by the expression pattern of the mucin molecules MUC5AC and MUC6 [22,23] and is characterized by a relative lack of intestinal phenotypic expression, including Cdx2 [24]. According to these findings, the targets of EBV infection and their subsequent transformation are seemingly the precursor cells possessing intrinsic differentiation potential toward the gastric cell type.

\section{Clinical Features}

The most useful modality for the diagnosis of GC is endoscopy. In one analysis, 124 GCs from 117 patients were examined by EBER1-ISH. Of the 124 tumors, 12 (9.7\%) were identified as EBV-associated tumors [25]. It is of note that EBV-associated GC predominantly localizes in the non-antrum part of the stomach (Figure 2) and appears as superficial depressed or ulcerated lesions. A histological feature of EBV-associated GC is a diffuse-type carcinoma accompanied by abundant lymphocyte infiltration (i.e., GCLS). In some patients, endoscopic ultrasound reveals a hypoechoic mass in the third hyperechoic layer reflecting submucosal nodules of lymphoid stroma, which is composed of carcinoma cells and infiltrating lymphocytes [26].

Figure 2. Endoscopic image of an Epstein-Barr virus-associated gastric carcinoma in the upper gastric body. The tumor shows a protruded shape probably because of the abundant lymphocyte infiltration.

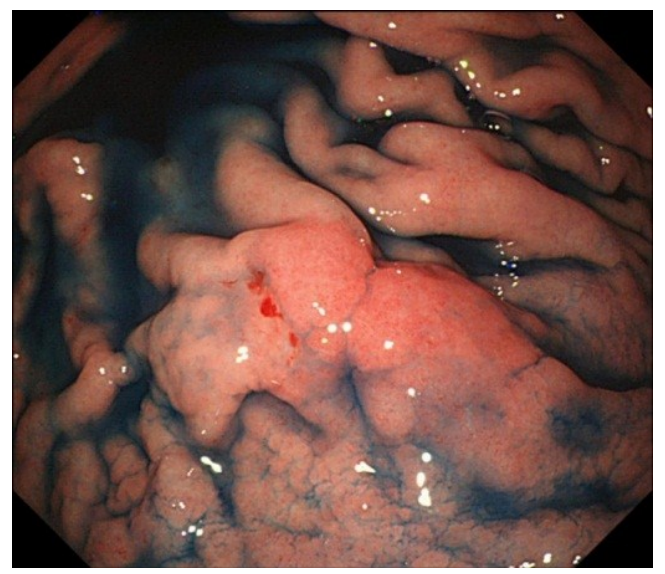

It is known that Helicobacter pylori is strongly related to cancer and is an etiological agent of chronic gastritis and intestinal metaplasia. It is distinctive that $H$. pylori-related gastritis frequently initiates in the antrum. In the case of EBV-associated GC, tumors are frequently located near the mucosal atrophic border, where mild to moderate atrophy is common [27]. We have frequently detected both EBV and $H$. pylori in the mucosa of patients with moderate chronic atrophic gastritis, where inflammatory cell infiltration is abundant, and not in the mucosa with marked atrophic gastritis, where inflammatory cell infiltration is scarce [28].

Gastric remnant cancer arises after distal gastrectomy for benign disease, which includes refractory gastric or duodenal ulcer disease and recurrent ulcer with gastric outlet obstruction. The incidence of gastric remnant cancer ranges from $1 \%$ to $7 \%$ of all GCs and is still increasing [29]. Gastric remnant 
carcinoma is frequently ( $25 \%$ to $41.2 \%$ ) associated with EBV infection. It is considered that the reflux of bile and pancreatic juice causes regenerative atypia and cell proliferation in epithelial cells [30]. Atrophic change of remnant gastritis in Billroth-II anastomoses is frequently accompanied by EBV-positive gastric remnant carcinoma [31]. Gastritis cystica polyposa, frequently observed in the remnant stomach, is a suspected precursor lesion of EBV-associated GC, but no direct evidence of EBV infection in these lesions has been found [32].

\section{Treatment and Prognosis of EBV-Associated GC}

The current therapy for EBV-associated GC does not use any special methods. Because undifferentiated-type cancer is prevalent in EBV-associated GC, most of these tumors are removed by surgical resection. Early EBV-associated GC has a low frequency of lymph node metastasis. Endoscopic treatment can be applied in such cases. The authors experienced a case of early EBV-associated GC with submucosal invasion in which palliative endoscopic treatment was performed. No recurrence was observed in the patient for more than 4 years [33]. A clinicopathological study in The Netherlands showed that EBV-associated GC has a significantly low frequency of lymph node metastasis compared with EBV-negative stomach cancer, resulting in a better prognosis than that with the EBV-negative cases [34]. A recent meta-analysis revealed that EBV-associated GC showed an infrequent tendency toward lymph node metastasis. After adjustment for TNM stage and other prognostic indicators, EBV positivity was associated with lower mortality [35]. Further studies are needed to identify the mechanisms underlying this prognostic association.

\section{Growth-Promoting Effects of EBV in Epithelial Cells}

\subsection{Models of EBV Infection of Gastric Epithelial Cells}

EBV infects both B lymphocytes and epithelial cells because the virus has been discovered in Burkitt lymphoma cells, Hodgkin cells, nasopharyngeal carcinoma cells, and GC cells. Experimental EBV infection of B cells is very efficient because EBV uses CD21, a high-affinity receptor, for its entry into the cell [36,37]. However, epithelial cells are CD21 negative, and infection of epithelial cells could not be achieved for a long time, not until CD21 expression was overcome by gene transfer [38,39]. Infection of EBV with human gastric epithelial cells was experimentally proved by our group [40], and EBV-infected gastric cells (AGS) have been established by Marquitz et al. [41]. A recombinant EBV with a neomycin resistance gene [42,43] was used for epithelial infection, and thus, epithelial cells, which do not express a CD21 EBV receptor, could be infected with EBV. This infection of CD21-negative epithelial cells was not blocked by anti-CD21 monoclonal antibody [40]. Next, EBV was efficiently transferred to epithelial cells by mixing epithelial cells with recombinant EBV-producing B cells [44]. There are several epithelial cell lines, such as CNE1 and HONE1, which can achieve experimental infection with EBV. Instead of these cell lines, SNU-719 cells [45], NCC24 cells [46], and KT cells [47] are a few of the cell types that retain the same clonal EBV genome and the pattern of EBV gene expression (type I EBV) as that in the original tumor biopsy. The KT cell is a good in vivo model of EBV-associated GC and expresses high IL-1 $\beta$ compared with EBV-negative gastric tumor cells [48]. 


\subsection{Growth-Promoting Effects of EBV}

EBV immortalizes B cells in vitro. EBNA 2 and latent membrane protein 1 (LMP1) appear to play the most important roles in the immortalization of lymphocytes. However, they are not expressed in EBV-associated GC, raising doubts about the importance of the presence of EBV. We attempted to infect gastric primary culture cells with EBV [49]. Primary gastric epithelial cells from healthy gastric mucosal biopsies were infected with recombinant EBV carrying a neomycin resistance gene, and infected cells were selected for using G418. As a result, we repeatedly separated cell clones that could be maintained for at least 300 generations. The selected EBV-infected cells expressed Qp-driven EBNA 1, EBER, BARTs, and latent membrane protein 2A (LMP2A). The pattern of latent gene expression was similar to EBV-associated GC. The EBV-infected clones had higher proliferation rates and at least twice the cell saturation density compared with non-infected clones into which the neomycin resistance gene had been introduced as a control, and the malignant phenotype was confirmed by colony formation in soft agar and tumorigenicity in SCID mice. EBV infection also promoted growth of gastric cancer cell lines NU-GC-3 and AGS $[41,49]$.

\section{Virus and Host Interactions at the Molecular Level}

\subsection{Genetic Alterations in EBV-Associated GC}

In EBV-associated GC, studies of genetic alteration are limited. Van Rees et al. [50] and Chong et al. [51] reported that chromosomal losses were extremely rare in EBV-associated GC in contrast to the high frequency in EBV-negative GC. Chromosomal aberrations in EBV-associated GCs were globally tested by comparative genomic hybridization. Zur Hausen et al. showed that loss of chromosomes $4 \mathrm{p}, 11 \mathrm{p}$, and 18q was distinct in EBV-associated GCs [52]. 18q harbors the DCC and SMAD4 genes, which are known tumor-suppressor genes. Chan et al. reported that gains in chromosome 11 copy numbers are common in EBV-associated malignancy including EBV-positive GC, lung cancer, and lymphoma [53]. As well, microsatellite instability is not common in EBV-associated GC [54]. Similarly, p53 mutation and overexpression are not frequent in EBV-associated GCs $[55,56]$. These findings indicate that genetic abnormality is not the major pathway to the development of EBV-associated GC.

\subsection{DNA Hypermethylation in EBV and Host Genomes}

Methylation of the tumor suppressor gene is a key abnormality in EBV-associated GC [57-59]. In tumor cells of EBV-associated GC, CpG island methylation is frequently observed at promoters of various tumor-related genes, which must take important parts in the development and progression of gastric cancer [60]. Methylation frequencies of several tumor suppressor genes, APC, PTEN, and RASSF1A, and cell adhesion molecules, THBS1 and E-cadherin, were reported to be significantly higher in EBV-associated GC [61-63]. Because demethylation agents induce lytic EBV infection in latently EBV-infected cells followed by apoptotic cell death, the therapeutic application of demethylating agents may lead to the lysis of cancer cells [64]. These facts strongly support possible application of demethylating agents to the medical treatment of EBV-associated GC. 
We compared methylation status between EBV-associated GCs and EBV-negative controls whose age, sex, histology, depth of invasion, and stage were matched. EBV-associated GCs showed higher methylation frequencies in 12 of 16 tumor-related genes compared with EBV-negative controls. The frequency of methylation at 6 specific loci (MINT2, MINT31, p14, p16, p73, and RUNX3) was significantly higher in EBV-associated GCs than in EBV-negative controls [65]. Moreover, the DNA methylation status in the naturally derived EBV-positive gastric adenocarcinoma cell line SNU-719 was also examined by the method of methylated $\mathrm{CpG}$ island recovery on chip assay [66]. Expression of several genes was regulated by DNA methylation in EBV-associated GC. The methylation frequencies of p73, BLU, FSD1, BCL7A, MARK1, SCRN1, and NKX3.1 were significantly higher in EBV-associated GC than in EBV-negative GC [66].

The precise molecular mechanism that induces host DNA methylation during the early stage of EBV infection of the gastric epithelium is not fully understood. LMP2A is reported to induce the phosphorylation of STAT3, which activates DNA methyltransferase 1 (DNMT1) transcription and causes loss of PTEN expression through $\mathrm{CpG}$ island methylation of the PTEN promoter in EBV-associated GC [67]. However, LMP2A is not expressed in every case of EBV-associated GC [68], and EBV-associated GC patients are usually negative for LMP2A antibody [69]. LMP1 can also induce aberrant DNA methylation by activating DNMT1 through the JNK signaling pathway [70] and inducing DNA methylation of host cells [71]. However, LMP1 is scarcely expressed, and LMP1 protein is generally absent in EBV-associated GC [72]. Methylation of similar genes has been reported in hepatitis $\mathrm{B}$ and $\mathrm{C}[73,74]$, suggesting that there must be a common mechanism underlying the formation of infection-associated cancers.

The status of DNA methylation in the EBV genome was intensively investigated [75]. The expression of EBV latent genes is strictly regulated through viral DNA methylation in EBV-infected cells. The $\mathrm{Cp} / \mathrm{Wp}$ EBNA promoters are known to transcribe all EBNAs. However, in Burkitt lymphoma and nasopharyngeal carcinoma, the $\mathrm{Cp} / \mathrm{Wp}$ promoters are methylated and the only EBNA1 promoter, Qp, is used instead [76,77]. Moreover, in EBV-positive nasopharyngeal carcinoma, LMP1 expression is down-regulated by methylation in its promoter region [78]. The pattern of latent gene expression in EBV-positive GCs is similar to that of Burkitt lymphoma, in which only Qp is actively used [7]. These results indicate that the methylation status of the EBV genome regulates the pattern of latent gene expression in EBV-positive tumor cells. Because methylation occurs on viral DNA in EBV-associated GC cells, methylation of host cell DNA may also occur, for example, on tumor suppressor genes that regulate the cell cycle and apoptosis. Aberrant DNA methylation might occur in EBV-positive cells, thus promoting the development and progression of EBV-associated GC (Figure 3).

\subsection{EBV Latent Genes and Host Interaction}

Iwakiri et al. reported that EBV infection promoted growth of gastric cancer cells by increased production of insulin-like growth factor (IGF)-1 as an autocrine growth factor. It was also revealed that EBERs are responsible for the induction of IGF-1 [79]. The oncogenic role of EBERs has been reported for inhibition of apoptosis in the human epithelial cell line Intestine 407 [80]. EBER was found to bind double-stranded RNA-dependent protein kinase $\mathrm{R}$, an interferon-inducible serine/threonine kinase, and abrogate its kinase activity. These results indicate that EBER contributes to the maintenance of epitheloid malignancy. 
Figure 3. Aberrant DNA methylation might lead to the development and progression of Epstein-Barr virus (EBV)-associated gastric carcinoma. DNMT, DNA methyltransferase.
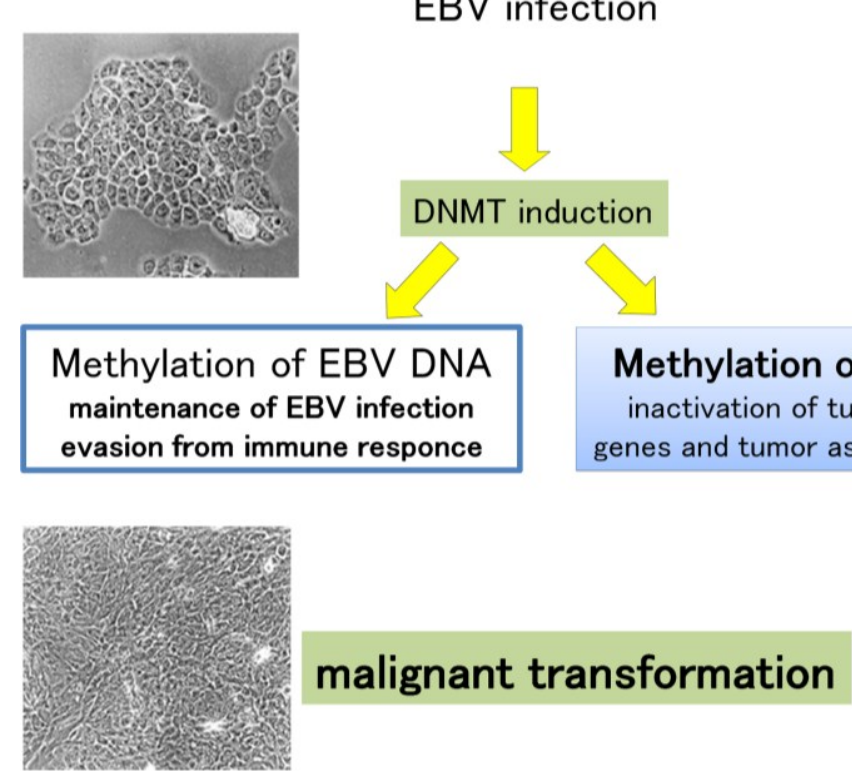

Methylation of host DNA

inactivation of tumor suppressor genes and tumor associated antigen

The oncogenic role of other genes such as BARF1 (BamHI A rightward open reading frame 1) [81] and LMP2A [67,82] has also been reported. The expression of the EBV-encoded oncogene BARF1 has been reported in EBV-associated GC. Wiech et al. reported that cyclin D1 is induced in BARF1-transfected epithelial cells and is overexpressed in EBV-associated GC [83]. LMP2A is reported to inhibit transforming growth factor-b1-induced apoptosis in a GC cell line [84]. Recently, it was demonstrated that LMP2A upregulated cellular survivin gene expression through the nuclear factor-kB pathway in GC cell lines with EBV infection [82]. In addition, LMP2A upregulates cellular DNMT1 in EBV-associated GC through the phosphorylation of STAT3, causing promoter hypermethylation of a tumor suppressor gene, PTEN [67].

\subsection{EBV microRNA and Gastric Cancer}

A microRNA (miRNA) is a small (20 to 25 nucleotides) non-coding RNA derived from double-stranded RNAs, which functions in RNA silencing and post-transcriptional regulation of gene expression. miRNA is incorporated into the RNA-induced silencing complex (RISC) in cytosol, binds to the 3' un-translated region (UTR) of mRNA, and then silences translation by destabilizing mRNA through shortening of its poly A tail [85]. miRNA is found in plants, animals, and some viruses. EBV is one of the first viruses reported to contain viral miRNA, the genome of which codes 25 miRNA precursors and produces 44 kinds of different miRNAs [86,87]. A number of mRNA targets by EBV miRNAs have been reported mainly in B lymphocytes via the bioinformatics approach $[88,89]$. Recent results of EBV miRNA targets using gastric epithelial cells are introduced in this section.

Choy et al. reported on the regulation of p53 up-regulated modulator of apoptosis (PUMA) by an EBV miRNA, miR-BART5-5p, which is abundantly expressed in nasopharyngeal carcinoma and EBV-associated GC cells [90]. Marquitz et al. showed that in vitro infection of an AGS cell line with EBV alters the growth properties of the cells and induces growth in soft agar in accordance with high levels of expression of the BamHI A rightward transcript (BART) miRNAs [41]. They showed 
downregulation of a tumor suppressor gene, PTEN, cellular adhesion proteins, integrin alpha 5 and alpha V, and signal transducer STAT6. These results suggested that the expression of EBV miRNA highly influences the genesis of EBV-associated GC. Choi et al. also investigated an AGS cell line and reported that the $3^{\prime}$ untranslated region of baculovirus inhibitor of apoptosis repeat-containing ubiquitin-conjugating enzyme (BRUCE) was affected by EBV miR-BART15-3p [91]. miR-BART miRNAs target many other anti-apoptotic genes; however, the precise roles of each gene for tumor formation are still not well understood.

Many research groups reported expression of EBV miRNAs in gastric cancer cells and histological samples from gastric cancers [92,93]. It is of note that YCCEL1 and SNU-719 cell lines are derived from a gastric cancer patient, respectively, and maintain viral episomes. Seemingly, this is the reason why these cell lines show expression profiles of EBV miRNAs similar to samples from gastric cancer patients [94-96]. These two cell lines are expected to become important tools for the study of EBV miRNA.

\section{Summary}

Considerable data suggest that EBV can increase cell proliferation and survival; and through these effects; EBV may directly contribute to the development of EBV-associated GC. This tumor-promoting effect seems to involve multiple mechanisms; because EBV affects several host proteins and pathways that normally promote apoptosis and regulate cell proliferation.

\section{Acknowledgments}

This study was supported in part by a Grant-in-Aid for Scientific Research from the Ministry of Education; Culture; Science and Technology of Japan (No. 23590534 to Hironori Yoshiyama and No. 26460938 to Jun Nishikawa) and in part by a Grant for Joint Research Program of the Institute for Genetic Medicine; Hokkaido University (to Hironori Yoshiyama).

\section{Author Contributions}

Conception and design of the study: Jun Nishikawa, Hironori Yoshiyama. Collection and assembly of data: Hisashi Iizasa, Yuichi Kenehiro, Munetaka Nakamura, Junichi Nishimura, Mari Saito, Takeshi Okamoto, Kouhei Sakai, Yutaka Suehiro, and Atsunori Oga. Critical revision and final approval of the article: Takahiro Yamasaki, Hideo Yanai, and Isao Sakaida.

\section{Conflicts of Interest}

The authors declare no conflict of interest.

\section{References}

1. Zur Hausen, H.; Schulte-Holthausen, H.; Klein, G.; Henle, W.; Henle, G.; Clifford, P.; Santesson, L. EBV DNA in biopsies of Burkitt tumours and anaplastic carcinomas of the nasopharynx. Nature 1970, 228, 1056-1058. 
2. Young, L.; Alfieri, C.; Hennessy, K.; Evans, H.; O’Hara, C.; Anderson, K.C.; Ritz, J.; Shapiro, R.S.; Rickinson, A.; Kieff, E.; et al. Expression of Epstein-Barr virus transformation-associated genes in tissues of patients with EBV lymphoproliferative disease. N. Engl. J. Med. 1989, 321, 1080-1085.

3. Rickinson, A.B.; Kieff, E. Epstein-Barr virus. In Fields Virology, 5th ed.; Fields, B.N., Knipe, D.M., Howley, P.M., Eds.; Lippincott-Williams \& Wilkins: Philadelphia, PA, USA, 2007; pp. 2655-2700.

4. Burke, A.P.; Yen, T.S.; Shekitka, K.M.; Sobin, L.H. Lymphoepithelial carcinoma of the stomach with Epstein-Barr virus demonstrated by polymerase chain reaction. Mod. Pathol. 1990, 3, 377-380.

5. Shibata, D.; Weiss, L.M. Epstein-Barr virus-associated gastric adenocarcinoma. Am. J. Pathol. 1992, 140, 769-774.

6. Tokunaga, M.; Land, C.E.; Uemura, Y.; Tokudome, T.; Tanaka, S.; Sato, E. Epstein-Barr virus in gastric carcinoma. Am. J. Pathol. 1993, 143, 1250-1254.

7. Imai, S.; Koizumi, S.; Sugiura, M.; Tokunaga, M.; Uemura, Y.; Yamamoto, N.; Tanaka, S.; Sato, E.; Osato, T. Gastric carcinoma: Monoclonal epithelial malignant cells expressing Epstein-Barr virus latent infection protein. Proc. Natl. Acad. Sci. USA 1994, 91, 9131-9135.

8. Fukayama, M.; Hayashi, Y.; Iwasaki, Y.; Chong, J.; Ooba, T.; Takizawa, T.; Koike, M.; Mizutani, S.; Miyaki, M.; Hirai, K. Epstein-Barr virus-associated gastric carcinoma and Epstein-Barr virus infection of the stomach. Lab. Investig. 1994, 71, 73-81.

9. Ferlay, J.; Shin, H.R.; Bray, F.; Forman, D.; Mathers, C.; Parkin, D.M. Estimates of worldwide burden of cancer in 2008: GLOBOCAN 2008. Int. J. Cancer 2010, 127, 2893-2917.

10. Takada, K. Epstein-Barr virus and gastric carcinoma. Mol. Pathol. 2000, 53, 255-261.

11. Tokunaga, M.; Uemura, Y.; Tokudome, T.; Ishidate, T.; Masuda, H.; Okazaki, E.; Kaneko, K.; Naoe, S.; Ito, M.; Okamura, A.; et al. Epstein-Barr virus related gastric cancer in Japan: A molecular patho-epidemiological study. Acta Pathol. Jpn. 1993, 43, 574-581.

12. Lee, J.H.; Kim, S.H.; Han, S.H.; An, J.S.; Lee, E.S.; Kim, Y.S. Clinicopathological and molecular characteristics of Epstein-Barr virus-associated gastric carcinoma: A meta-analysis. J. Gastroenterol. Hepatol. 2009, 24, 354-365.

13. Murphy, G.; Pfeiffer, R.; Camargo, M.C.; Rabkin, C.S. Meta-analysis shows that prevalence of Epstein-Barr virus-positive gastric cancer differs based on sex and anatomic location. Gastroenterology 2009, 137, 824-833.

14. Akiba, S.; Koriyama, C.; Herrera-Goepfert, R.; Eizuru, Y. Epstein-Barr virus associated gastric carcinoma: Epidemiological and clinicopathological features. Cancer Sci. 2008, 99, 195-201.

15. Koriyama, C.; Akiba, S.; Minakami, Y.; Eizuru, Y. Environmental factors related to Epstein-Barr virus-associated gastric cancer in Japan. J. Exp. Clin. Cancer Res. 2005, 24, 547-553.

16. Camargo, M.C.; Koriyama, C.; Matsuo, K.; Kim, W.H.; Herrera-Goepfert, R.; Liao, L.M.; Eurgast-EPIC Group; Yu, J.; Carrasquilla, G.; Sung, J.J.; et al. Case-case comparison of smoking and alcohol risk associations with Epstein-Barr virus-positive gastric cancer. Int. J. Cancer 2014, 134, 948-953.

17. Oda, K.; Tamaru, J.; Takenouchi, T.; Mikata, A.; Nunomura, M.; Saitoh, N.; Sarashina, H.; Nakajima, N. Association of Epstein-Barr virus with gastric carcinoma with lymphoid stroma. Am. J. Pathol. 1993, 143, 1063-1071. 
18. Nakamura, S.; Ueki, T.; Yao, T.; Ueyama, T.; Tsuneyoshi, M. Epstein-Barr virus in gastric carcinoma with lymphoid stroma. Special reference to its detection by the polymerase chain reaction and in situ hybridization in 99 tumors, including a morphologic analysis. Cancer 1994, 73, 2239-2249.

19. Matsunou, H.; Konishi, F.; Hori, H.; Ikeda, T.; Sasaki, K.; Hirose, Y.; Yamamichi, N. Characteristics of Epstein-Barr virus-associated gastric carcinoma with lymphoid stroma in Japan. Cancer 1996, 77, 1998-2004.

20. Watanabe, H.; Enjoji, M.; Imai, T. Gastric carcinoma with lymphoid stroma. Its morphologic characteristics and prognostic correlations. Cancer 1976, 38, 232-243.

21. Fukayama, M. Epstein-Barr virus and gastric carcinoma. Pathol. Int. 2010, 60, 337-350.

22. Nakamura, Y.; Yanai, H.; Kitou, T.; Matsubara, Y.; Hirano, A.; Okamoto, T.; Yoshida, T.; Okita, K.; Matsusaki, K. Mucin and differentiation in Epstein-Barr virus-associated gastric carcinoma. Hepatogastroenterology 2005, 52, 1066-1070.

23. Barua, R.R.; Uozaki, H.; Chong, J.M.; Ushiku, T.; Hino, R.; Chang, M.S.; Nagai, H.; Fukayama, M. Phenotype analysis by MUC2, MUC5AC, MUC6, and CD10 expression in Epstein-Barr virus-associated gastric carcinoma. J. Gastroenterol. 2006, 41, 733-739.

24. Hirano, N.; Tsukamoto, T.; Mizoshita, T.; Koriyama, C.; Akiba, S.; Campos, F.; Carrasquilla, G.; Carrascal, E.; Cao, X.; Toyoda, T.; et al. Down regulation of gastric and intestinal phenotypic expression in Epstein-Barr virus-associated stomach cancers. Histol. Histopathol. 2007, 22, 641-649.

25. Yanai, H.; Nishikawa, J.; Mizugaki, Y.; Shimizu, N.; Takada, K.; Matsusaki, K.; Toda, T.; Matsumoto, Y.; Tada, M.; Okita, K. Endoscopic and pathologic features of Epstein-Barr virus-associated gastric carcinoma. Gastrointest. Endosc. 1997, 45, 236-242.

26. Nishikawa, J.; Yanai, H.; Mizugaki, Y.; Takada, K.; Tada, M.; Okita, K. Case report: Hypoechoic submucosal nodules: A sign of Epstein-Barr virus-associated early gastric cancer. J. Gastroenterol. Hepatol. 1998, 13, 585-590.

27. Yanai, H.; Murakami, T.; Yoshiyama, H.; Takeuchi, H.; Nishikawa, J.; Nakamura, H.; Okita, K.; Miura, O.; Shimizu, N.; Takada, K. Epstein-Barr virus-associated gastric carcinoma and atrophic gastritis. J. Clin. Gastroenterol. 1999, 29, 39-43.

28. Hirano, A.; Yanai, H.; Shimizu, N.; Okamoto, T.; Matsubara, Y.; Yamamoto, K.; Okita, K. Evaluation of Epstein-Barr virus DNA load in gastric mucosa with chronic atrophic gastritis using a real-time quantitative PCR assay. Int. J. Gastrointest. Cancer 2003, 34, 87-94.

29. Lagergren, J.; Lindam, A.; Mason, R.M. Gastric stump cancer after distal gastrectomy for benign gastric ulcer in a population-based study. Int. J. Cancer 2012, 131, E1048-E1052.

30. Yamamoto, N.; Tokunaga, M.; Uemura, Y.; Tanaka, S.; Shirahama, H.; Nakamura, T.; Land, C.E.; Sato, E. Epstein-Barr virus and gastric remnant cancer. Cancer 1994, 74, 805-809.

31. Nishikawa, J.; Yanai, H.; Hirano, A.; Okamoto, T.; Nakamura, H.; Matsusaki, K.; Kawano, T.; Miura, O.; Okita, K. High prevalence of Epstein-Barr virus in gastric remnant carcinoma after Billroth-II reconstruction. Scand. J. Gastroenterol. 2002, 37, 825-829.

32. Choi, M.G.; Jeong, J.Y.; Kim, K.M.; Bae, J.M.; Noh, J.H.; Sohn, T.S.; Kim, S. Clinical significance of gastritis cystica profunda and its association with Epstein-Barr virus in gastric cancer. Cancer 2012, 118, 5227-5233.

33. Nishikawa, J.; Saito, M.; Kiyotoki, S.; Hamabe, K.; Okamoto, T.; Yanai, H.; Sakaida, I. Epstein-Barr virus associated gastric carcinoma (In Japanese). Biotherapy 2010, 24, 429-434. 
34. Van Beek, J.; zur Hausen, A.; Klein Kranenbarg, E.; van de Velde, C.J.; Middeldorp, J.M.; van den Brule, A.J.; Meijer, C.J.; Bloemena, E. EBV-positive gastric adenocarcinomas: A distinct clinicopathologic entity with a low frequency of lymph node involvement. J. Clin. Oncol. 2004, 22, 664-670.

35. Camargo, M.C.; Kim, W.H.; Chiaravalli, A.M.; Kim, K.M.; Corvalan, A.H.; Matsuo, K.; Yu, J.; Sung, J.J.; Herrera-Goepfert, R.; Meneses-Gonzalez, F.; et al. Improved survival of gastric cancer with tumour Epstein-Barr virus positivity: An international pooled analysis. Gut 2014, 63, 236-243.

36. Fingeroth, J.D.; Weis, J.J.; Tedder, T.F.; Strominger, J.L.; Biro, P.A.; Fearon, D.T. Epstein-Barr virus receptor of human B lymphocytes is the C3d receptor CR2. Proc. Natl. Acad. Sci. USA 1984, $81,4510-4514$.

37. Tanner, J.; Weis, J.; Fearon, D.; Whang, Y.; Kieff, E. Epstein-Barr virus gp350/220 binding to the B lymphocyte C3d receptor mediates adsorption, capping, and endocytosis. Cell 1987, 50, 203-213.

38. Li, Q.X.; Young, L.S.; Niedobitek, G.; Dawson, C.W.; Birkenbach, M.; Wang, F.; Rickinson, A.B. Epstein-Barr virus infection and replication in a human epithelial cell system. Nature 1992, 356, 347-350.

39. Fingeroth, J.D.; Diamond, M.E.; Sage, D.R.; Hayman, J.; Yates, J.L. CD21-Dependent infection of an epithelial cell line, 293, by Epstein-Barr virus. J. Virol. 1999, 73, 2115-2125.

40. Yoshiyama, H.; Imai, S.; Shimizu, N.; Takada, K. Epstein-Barr virus infection to human gastric carcinoma cells: Implication of the existence of a new virus receptor different from CD21. J. Virol. 1997, 71, 5688-5691.

41. Marquitz, A.R.; Mathur, A.; Shair, K.H.; Raab-Traub, N. Infection of Epstein-Barr virus in a gastric carcinoma cell line induces anchorage independence and global changes in gene expression. Proc. Natl. Acad. Sci. USA 2012, 109, 9593-9598.

42. Yoshiyama, H.; Shimizu, N.; Takada, K. Persistent Epstein-Barr virus infection in a human T-cell line: Unique program of latent virus expression. EMBO J. 1995, 14, 3706-3711.

43. Shimizu, N.; Yoshiyama, H.; Takada, K. Clonal propagation of Epstein-Barr virus (EBV) recombinants in EBV-negative Akata cells. J. Virol. 1996, 70, 7260-7263.

44. Imai, S.; Nishikawa, J.; Takada, K. Cell-to-cell contact as an efficient mode of Epstein-Barr virus infection of diverse human epithelial cells. J. Virol. 1998, 72, 4371-4378.

45. Oh, S.T.; Seo, J.S.; Moon, U.Y.; Kang, K.H.; Shin, D.J.; Yoon, S.K.; Kim, W.H.; Park, J.G.; Lee, S.K. A naturally derived gastric cancer cell line shows latency I Epstein-Barr virus infection closely resembling EBV-associated gastric cancer. Virology 2004, 320, 330-336.

46. Ku, J.L.; Kim, K.H.; Choi, J.S.; Kim, S.H.; Shin, Y.K.; Chang, H.J.; Bae, J.M.; Kim, Y.W.; Lee, J.H.; Yang, H.K.; et al. Establishment and characterization of six human gastric carcinoma cell lines, including one naturally infected with Epstein-Barr virus. Cell. Oncol. (Dordr.) 2012, 35, 127-136.

47. Iwasaki, Y.; Chong, J.M.; Hayashi, Y.; Ikeno, R.; Arai, K.; Kitamura, M.; Koike, M.; Hirai, K.; Fukayama, M. Establishment and characterization of a human Epstein-Barr virus-associated gastric carcinoma in SCID mice. J. Virol. 1998, 72, 8321-8326.

48. Chong, J.M.; Sakuma, K.; Sudo, M.; Osawa, T.; Ohara, E.; Uozaki, H.; Shibahara, J.; Kuroiwa, K.; Tominaga, S.; Hippo, Y.; et al. Interleukin-1beta expression in human gastric carcinoma with Epstein-Barr virus infection. J. Virol. 2002, 76, 6825-6831. 
49. Nishikawa, J.; Imai, S.; Oda, T.; Kojima, T.; Okita, K.; Takada, K. Epstein-Barr virus promotes epithelial cell growth in the absence of EBNA2 and LMP1 expression. J. Virol. 1999, 73, 1286-1292.

50. Van Rees, B.P.; Caspers, E.; zur Hausen, A.; van den Brule, A.; Drillenburg, P.; Weterman, M.A.; Offerhaus, G.J. Different pattern of allelic loss in Epstein-Barr virus-positive gastric cancer with emphasis on the p53 tumor suppressor pathway. Am. J. Pathol. 2002, 161, 1207-1213.

51. Chong, J.M.; Fukayama, M.; Hayashi, Y.; Takizawa, T.; Koike, M.; Konishi, M.; Kikuchi-Yanoshita, R.; Miyaki, M. Microsatellite instability in the progression of gastric carcinoma. Cancer Res. 1994, 54, 4595-4597.

52. Zur Hausen, A.; van Grieken, N.C.; Meijer, G.A.; Hermsen, M.A.; Bloemena, E.; Meuwissen, S.G.; Baak, J.P.; Meijer, C.J.; Kuipers, E.J.; van den Brule, A.J. Distinct chromosomal aberrations in Epstein-Barr virus-carrying gastric carcinomas tested by comparative genomic hybridization. Gastroenterology 2001, 121, 612-618.

53. Chan, W.Y.; Chan, A.B.; Liu, A.Y.; Chow, J.H.; Ng, E.K.; Chung, S.S. Chromosome 11 copy number gains and Epstein-Barr virus-associated malignancies. Diagn. Mol. Pathol. 2001, 10, 223-227.

54. Chang, M.S.; Lee, H.S.; Kim, H.S.; Kim, S.H.; Choi, S.I.; Lee, B.L.; Kim, C.W.; Kim, Y.I.; Yang, M.; Kim, W.H. Epstein-Barr virus and microsatellite instability in gastric carcinogenesis. J. Pathol. 2003, 199, 447-452.

55. Gulley, M.L.; Pulitzer, D.R.; Eagan, P.A.; Schneider, B.G. Epstein-Barr virus infection is an early event in gastric carcinogenesis and is independent of bcl-2 expression and p53 accumulation. Hum. Pathol. 1996, 27, 20-27.

56. Moritani, S.; Sugihara, H.; Kushima, R.; Hattori, T. Different roles of p53 between Epstein-Barr virus-positive and -negative gastric carcinomas of matched histology. Virchows Arch. 2002, 440, 367-375.

57. Kusano, M.; Toyota, M.; Suzuki, H.; Akino, K.; Aoki, F.; Fujita, M.; Hosokawa, M.; Shinomura, Y.; Imai, K.; Tokino, T. Genetic, epigenetic, and clinicopathologic features of gastric carcinomas with the $\mathrm{CpG}$ island methylator phenotype and an association with Epstein-Barr virus. Cancer 2006, 106, 1467-1479.

58. Chang, M.S.; Uozaki, H.; Chong, J.M.; Ushiku, T.; Sakuma, K.; Ishikawa, S.; Hino, R.; Barua, R.R.; Iwasaki, Y.; Arai, K.; et al. CpG island methylation status in gastric carcinoma with and without infection of Epstein-Barr virus. Clin. Cancer Res. 2006, 12, 2995-3002.

59. Kaneda, A.; Matsusaka, K.; Aburatani, H.; Fukayama, M. Epstein-Barr virus infection as an epigenetic driver of tumorigenesis. Cancer Res. 2012, 72, 3445-3450.

60. Feinberg, A.P.; Tycko, B. The history of cancer epigenetics. Nat. Rev. Cancer 2004, 4, 143-153.

61. Kang, G.H.; Lee, S.; Kim, W.H.; Lee, H.W.; Kim, J.C.; Rhyu, M.G.; Ro, J.Y. Epstein-barr virus-positive gastric carcinoma demonstrates frequent aberrant methylation of multiple genes and constitutes CpG island methylator phenotype-positive gastric carcinoma. Am. J. Pathol. 2002, 160, 787-794.

62. Vo, Q.N.; Geradts, J.; Gulley, M.L.; Boudreau, D.A.; Bravo, J.C.; Schneider, B.G. Epstein-Barr virus in gastric adenocarcinomas: Association with ethnicity and CDKN2A promoter methylation. J. Clin. Pathol. 2002, 55, 669-675. 
63. Chong, J.M.; Sakuma, K.; Sudo, M.; Ushiku, T.; Uozaki, H.; Shibahara, J.; Nagai, H.; Funata, N.; Taniguchi, H.; Aburatani, H.; et al. Global and non-random CpG-island methylation in gastric carcinoma associated with Epstein-Barr virus. Cancer Sci. 2003, 94, 76-80.

64. Feng, W.H.; Hong, G.; Delecluse, H.J.; Kenney, S.C. Lytic induction therapy for Epstein-Barr virus-positive B-cell lymphomas. J. Virol. 2004, 78, 1893-1902.

65. Saito, M.; Nishikawa, J.; Okada, T.; Morishige, A.; Sakai, K.; Nakamura, M.; Kiyotoki, S.; Hamabe, K.; Okamoto, T.; Oga, A.; et al. Role of DNA methylation in the development of Epstein-Barr virus-associated gastric carcinoma. J. Med. Virol. 2013, 85, 121-127.

66. Okada, T.; Nakamura, M.; Nishikawa, J.; Sakai, K.; Zhang, Y.; Saito, M.; Morishige, A.; Oga, A.; Sasaki, K.; Suehiro, Y.; et al. Identification of genes specifically methylated in Epstein-Barr virus-associated gastric carcinomas. Cancer Sci. 2013, 104, 1309-1314.

67. Hino, R.; Uozaki, H.; Murakami, N.; Ushiku, T.; Shinozaki, A.; Ishikawa, S.; Morikawa, T.; Nakaya, T.; Sakatani, T.; Takada, K.; et al. Activation of DNA methyltransferase 1 by EBV latent membrane protein 2A leads to promoter hypermethylation of PTEN gene in gastric carcinoma. Cancer Res. 2009, 69, 2766-2774.

68. Luo, B.; Wang, Y.; Wang, X.F.; Liang, H.; Yan, L.P.; Huang, B.H.; Zhao, P. Expression of Epstein-Barr virus genes in EBV-associated gastric carcinomas. World J. Gastroenterol. 2005, 11 , 629-633.

69. Lennette, E.T.; Winberg, G.; Yadav, M.; Enblad, G.; Klein, G. Antibodies to LMP2A/2B in EBV-carrying malignancies. Eur. J. Cancer 1995, 31A, 1875-1878.

70. Tsai, C.L.; Li, H.P.; Lu, Y.J.; Hsueh, C.; Liang, Y.; Chen, C.L.; Tsao, S.W.; Tse, K.P.; Yu, J.S.; Chang, Y.S. Activation of DNA methyltransferase1 by EBV LMP1 Involves $c$-Jun NH(2)-terminal kinase signaling. Cancer Res. 2006, 66, 11668-11676.

71. Tsai, C.N.; Tsai, C.L.; Tse, K.P.; Chang, H.Y.; Chang, Y.S. The Epstein-Barr virus oncogene product, latent membrane protein 1, induces the downregulation of E-cadherin gene expression via activation of DNA methyltransferases. Proc. Natl. Acad. Sci. USA 2002, 99, 10084-10089.

72. Kida, Y.; Miyauchi, K.; Takano, Y. Gastric adenocarcinoma with differentiation to sarcomatous components associated with monoclonal Epstein-Barr virus infection and LMP-1 expression. Virchows Archiv. A Pathol. Anat. Histopathol. 1993, 423, 383-387.

73. Kanai, Y.; Hui, A.M.; Sun, L.; Ushijima, S.; Sakamoto, M.; Tsuda, H.; Hirohashi, S. DNA hypermethylation at the D17S5 locus and reduced HIC-1 mRNA expression are associated with hepatocarcinogenesis. Hepatology 1999, 29, 703-709.

74. Kondo, Y.; Kanai, Y.; Sakamoto, M.; Mizokami, M.; Ueda, R.; Hirohashi, S. Genetic instability and aberrant DNA methylation in chronic hepatitis and cirrhosis-A comprehensive study of loss of heterozygosity and microsatellite instability at 39 loci and DNA hypermethylation on $8 \mathrm{CpG}$ islands in microdissected specimens from patients with hepatocellular carcinoma. Hepatology 2000, 32, 970-979.

75. Niller, H.H.; Wolf, H.; Minarovits, J. Epigenetic dysregulation of the host cell genome in Epstein-Barr virus-associated neoplasia. Semin. Cancer Biol. 2009, 19, 158-164.

76. Masucci, M.G.; Contreras-Salazar, B.; Ragnar, E.; Falk, K.; Minarovits, J.; Ernberg, I.; Klein, G. 5-Azacytidine up regulates the expression of Epstein-Barr virus nuclear antigen 2 (EBNA-2) 
through EBNA-6 and latent membrane protein in the Burkitt's lymphoma line rael. J. Virol. 1989, 63, 3135-3141.

77. Ernberg, I.; Falk, K.; Minarovits, J.; Busson, P.; Tursz, T.; Masucci, M.G.; Klein, G. The role of methylation in the phenotype-dependent modulation of Epstein-Barr nuclear antigen 2 and latent membrane protein genes in cells latently infected with Epstein-Barr virus. J. Gen. Virol. 1989, 70, 2989-3002.

78. Hu, L.F.; Minarovits, J.; Cao, S.L.; Contreras-Salazar, B.; Rymo, L.; Falk, K.; Klein, G.; Ernberg, I. Variable expression of latent membrane protein in nasopharyngeal carcinoma can be related to methylation status of the Epstein-Barr virus BNLF-1 5'-flanking region. J. Virol. 1991, 65, 1558-1567.

79. Iwakiri, D.; Eizuru, Y.; Tokunaga, M.; Takada, K. Autocrine growth of Epstein-Barr virus-positive gastric carcinoma cells mediated by an Epstein-Barr virus-encoded small RNA. Cancer Res. 2003, 63, 7062-7067.

80. Nanbo, A.; Yoshiyama, H.; Takada, K. Epstein-Barr virus-encoded poly(A)-RNA confers resistance to apoptosis mediated through Fas by blocking the PKR pathway in human epithelial intestine 407 cells. J. Virol. 2005, 79, 12280-12285.

81. Seto, E.; Yang, L.; Middeldorp, J.; Sheen, T.S.; Chen, J.Y.; Fukayama, M.; Eizuru, Y.; Ooka, T.; Takada, K. Epstein-Barr virus (EBV)-encoded BARF1 gene is expressed in nasopharyngeal carcinoma and EBV-associated gastric carcinoma tissues in the absence of lytic gene expression. J. Med. Virol. 2005, 76, 82-88.

82. Hino, R.; Uozaki, H.; Inoue, Y.; Shintani, Y.; Ushiku, T.; Sakatani, T.; Takada, K.; Fukayama, M. Survival advantage of EBV-associated gastric carcinoma: Survivin up-regulation by viral latent membrane protein 2A. Cancer Res. 2008, 68, 1427-1435.

83. Wiech, T.; Nikolopoulos, E.; Lassman, S.; Heidt, T.; Schöpflin, A.; Sarbia, M.; Werner, M.; Shimizu, Y.; Sakka, E.; Ooka, T.; et al. Cyclin D1 expression is induced by viral BARF1 and is overexpressed in EBV-associated gastric cancer. Virchows Arch. 2008, 452, 621-627.

84. Fukuda, M.; Longnecker, R. Latent membrane protein $2 \mathrm{~A}$ inhibits transforming growth factor-beta 1-induced apoptosis through the phosphatidylinositol 3-kinase/Akt pathway. $J$ Virol. 2004, 78, 1697-1705.

85. Bartel, D.P. MicroRNAs: Target recognition and regulatory functions. Cell 2009, 136, 215-233.

86. Lung, R.W.; Tong, J.H.; To, K.F. Emerging roles of small Epstein-Barr virus derived non-coding RNAs in epithelial malignancy. Int. J. Mol. Sci. 2013, 14, 17378-17409.

87. Lung, R.W.; Tong J.H.; Sung, Y.M.; Leung, P.S.; Ng, D.C.; Chau, S.L.; Chan, A.W.; Ng, E.K.; Lo, K.W.; To, K.F. Modulation of LMP2A expression by a newly identified Epstein-Barr virus-encoded microRNA miR-BART22. Neoplasia 2009, 11, 1174-1184.

88. Iizasa, H.; Nanbo, A.; Nishikawa, J.; Jinushi, M.; Yoshiyama, H. Epstein-Barr Virus (EBV)-associated gastric carcinoma. Viruses 2012, 4, 3420-3439.

89. Iizasa, H.; Wulff, B.E.; Alla, N.R.; Maragkakis, M.; Megraw, M.; Hatzigeorgiou, A.; Iwakiri, D.; Takada, K.; Wiedmer, A.; Showe, L.; et al. Editing of Epstein-Barr virus-encoded BART6 microRNAs controls their dicer targeting and consequently affects viral latency. J. Biol. Chem. 2010, 285, 33358-33370. 
90. Choy, E.Y.; Siu, K.L.; Kok, K.H.; Lung, R.W.; Tsang, C.M.; To, K.F.; Kwong, D.L.; Tsao, S.W.; Jin, D.Y. An Epstein-Barr virus-encoded microRNA targets PUMA to promote host cell survival. J. Exp. Med. 2008, 205, 2551-2560.

91. Choi, H.; Lee, H.; Kim, S.R.; Gho, Y.S.; Lee, S.K. Epstein-Barr virus-encoded microRNA BART15-3p promotes cell apoptosis partially by targeting BRUCE. J. Virol. 2013, 87, 8135-8144.

92. Qiu, J.; Cosmopoulos, K.; Pegtel, M.; Hopmans, E.; Murray, P.; Middeldorp, J.; Shapiro, M.; Thorley-Lawson, D.A. A novel persistence associated EBV miRNA expression profile is disrupted in neoplasia. PLoS Pathog. 2011, 7, e1002193.

93. Marquitz, A.R.; Mathur, A.; Chugh, P.E.; Dittmer, D.P.; Raab-Traub, N. Expression profile of microRNAs in Epstein-Barr virus-infected AGS gastric carcinoma cells. J. Virol. 2014, 88, 1389-1393.

94. Kim, D.N.; Chae, H.S.; Oh, S.T.; Kang, J.H.; Park, C.H.; Park, W.S.; Takada, K.; Lee, J.M.; Lee, W.K.; Lee, S.K. Expression of viral microRNAs in Epstein-Barr virus-associated gastric carcinoma. J. Virol. 2007, 81, 1033-1036.

95. Kim, D.N.; Lee, S.K. Biogenesis of Epstein-Barr virus microRNAs. Mol. Cell. Biochem. 2012, 365, 203-210.

96. Kim, D.N.; Seo, M.K.; Choi, H.; Kim, S.Y.; Shin, H.J.; Yoon, A.R.; Tao, Q.; Rha, S.Y.; Lee, S.K. Characterization of naturally Epstein-Barr virus-infected gastric carcinoma cell line YCCEL1. J. Gen. Virol. 2013, 94, 497-506.

(C) 2014 by the authors; licensee MDPI, Basel, Switzerland. This article is an open access article distributed under the terms and conditions of the Creative Commons Attribution license (http://creativecommons.org/licenses/by/4.0/). 